made to the discrepancy of opinion among the consultants. The recovery of the patient, contrary to the prognosis of the first consultant, could not possibly have injured the reputation of the second consultant-quite the reverse. The natural conclusion of the patient and friends would have been that, as Dr. Johnson was wrong in his prognosis, he was, most probably, wrong in his treatment of the case-ergo, the recovery of the patient was owing to the second consultant. Taking it in every point of view, then, we conceive that, unless upon some very extraordinary occasion, where great difference of opinion obtains as to treatment, there should be no disclosure of such opinions to the friends. If great discrepancy of opinion, upon some important point of treatment, occurred, we think it would be more prudent for one of the parties to retire, or to request a third opinion to decide the question."

I have not a word to add, sir-I like to quote from good authority, when I find my own views written out in better language than I can command for them myself. Heart of the Commonwealth.

February 22, 1836.

\title{
EPIDEMIC MEASLES
}

BY MARSHALL S. PERRT, M.D. PHYSICIAN OF THE HOUSE OF INDUSTRY.

[Communicated for the Boston Medical and Surgica] Journal:]

THE following is an abstract, taken by Mr. Dorr, the resident student, from the daily record of 52 cases of measles, which occurred at the House of Industry in South Boston, during the months of November and December, 1835.

The measles have been uncommonly prevalent and fatal during the last four months in the city of Boston. The greater portion of those children who have been reported as having died of this disease, died of pneumonitis, which followed the eruption. At the House of Industry, inflammation of the mucous membrane of the large intestines was much the most formidable disease. In fact, to treat the cases there among young children with cathartics, was out of the question. Active cathartic medicines almost invariably induced diarrhœe of a severe character. Can this difference between the prominent local disease among children in private families and those in the asylum be owing to the difference in diet? Those who had bronchitis and pneumonitis were treated with ipecac. mustard poultices, warm baths and local bleeding in the early stages of the disease, and with some soothing expectorant medicine after the inflammatory symptoms had subsided. The two cases reported as having died of gangrene, were examined, and the mucous membrane of the large intestines was found softened, and redder than natural. This was the only morbid appearance found in the viscera. In the case of pneumonitis which proved fatal, both lungs were found diseased. Those cases that were not complicated with local inflammation, required little or no treatment. 


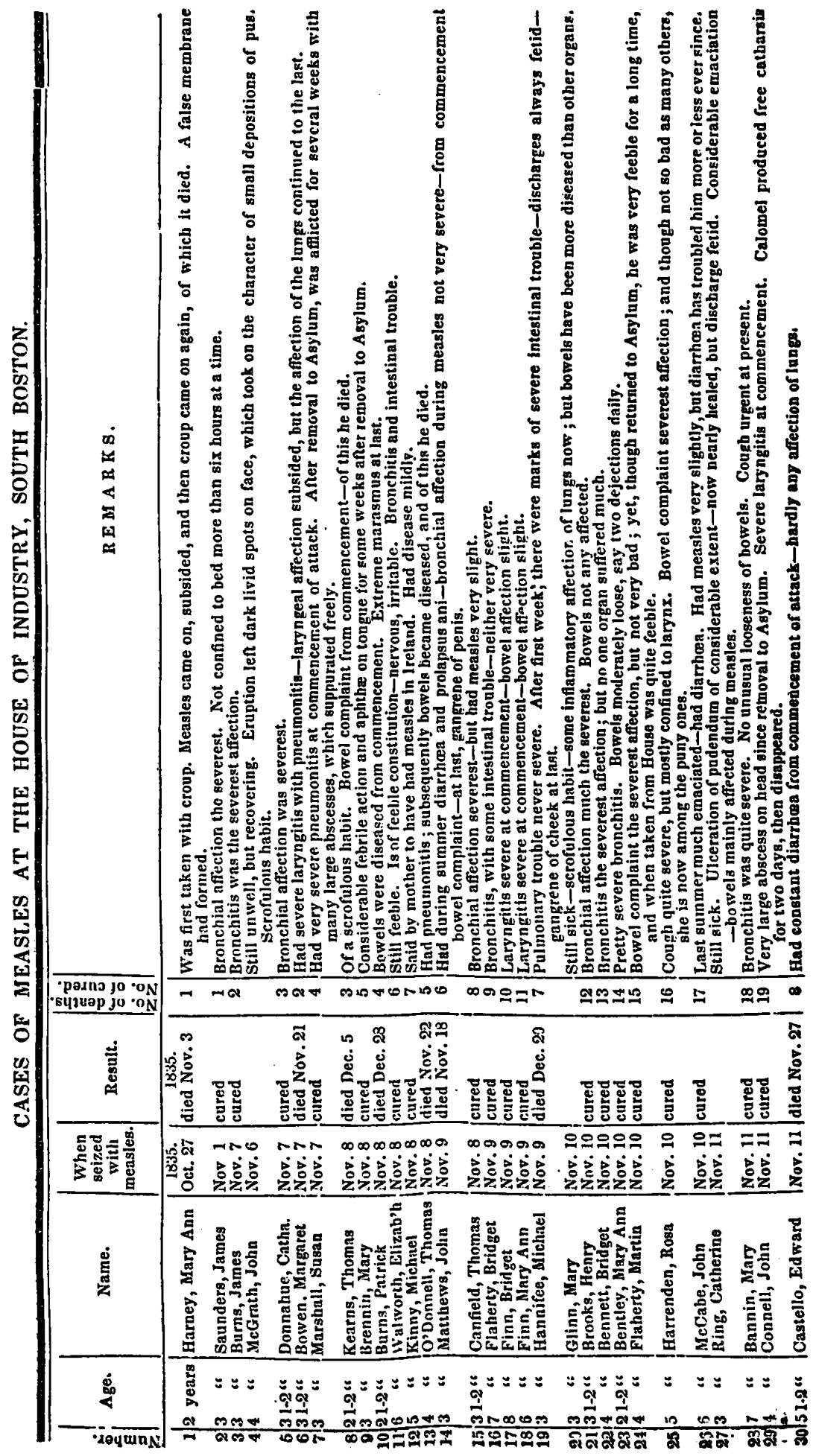




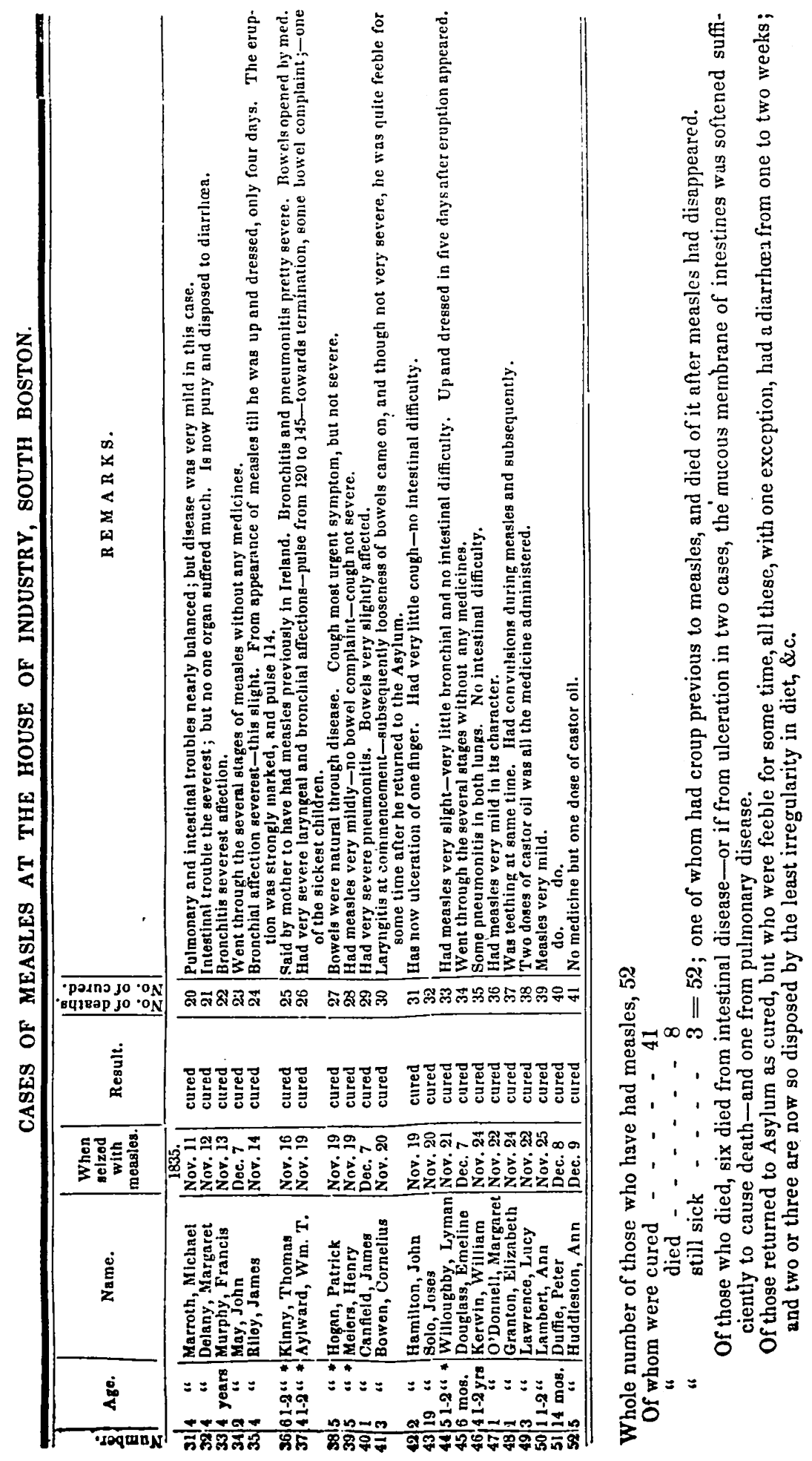

The Boston Medical and Surgical Journal as published by 
Of those wilo recovered,-Many of the children, especially nursing children, had measles very slightly. Some of the older children, also, were so mildly affected, that in the following list no account is made of them. Of those who had disease, in a severe form, complicated with measles-bronchitis, 15 ; laryngitis, 5 ; pneumonitis, 4 ; bowel complaint, not severe, yet the most prominent disease, 5 . With bronchitis, in several cases, some pneumonitis was connected ; but the bronchial affection was the severest, and accordingly they are stated as having had bronchitis. None who had bronchitis, or laryngitis, or pneumonitis alone, without any other complication, even if it were severe, died. The 4 stated above as having had bowel complaint more prominently than any other affection, had it rather as the result of irritating medicine, than as an untoward disposition in the intestinal canal to become seriously diseased; for often when those medicines were withlelkl, and soothing medicines given, the disease abated. Where bowel complaint started at commencement of attack of measles, it was alinost always unmanageable; and in those who died, four had it severely from the first. In these cases the autopsies showed an almost complete destruction of the mucous membrane of the large intestines, and, in two instances, of the stoniach also. This organ was in two cases found much corrugated. The boys who were at the Boys' Asylum, went through the different stages of measles with less serious complication than the smaller children, and when the complication was severe (as it in one case surely was), they seened to have more foundation for active treatinent. They are those against whose names $a^{*}$ is placed.

Of those who died,-Bowen, Margaret-both parents drunken and dissolute. Had been in asylum 6 montbs. A pparently pretty healthy. Harney, M. A.-father dissolute; mother drinks sometimes. Had been in asylum 1 week. Very delicate and rather feeble. Kearns, Thomas -father not known; mother dissolute. Had been in asylum 5 months. Very feeble constitution; ill last sumıner. Burns, Patrick-father died on passage; mother healthy. Had been in asylun 9 months. Very feeble constitution; ill in September and October. O'Donnell, Thomas -father supposed drunkard; mother crazy. Had been in asylum 9 nonths. Strong, healthy; very large head. Matthews, Joln-father supposed drunkard; mother decent woman. Had been in asylum 4 months. Very miserable constitution; sick all summer. Hannifee, Michael-parents dissolute. Had been in asylum 5 months. Rather feeble, but at times active. Castello, Edward-nothing known of parents. Had been in asylum 9 months. Thin; pale countenance; not much known.

Of those still living, but sick,-Glinn, Mary-nothing is known of her parents. Ring, Catherine-mother drunkard; father, nothing know'n. She came in with measles, in a collapsed state, from cold, exposure, \&c. McGrath, John-parents dissolute. In language of Superintendent, "Conceived in gin and brotight forth in alcohol."

General Remarks. - The asylum is a wooden building, two stories high, separate from the main building. It is divided into four principal rooms besides wash-rooms, \&c. ; two of these large rooms are for boys, 
and two for the smaller children, both boys and girls; two of these rooms on the lower floor are school rooms, measuring each $38+28 \mathrm{ft}$. and about $12 \mathrm{ft}$. in height, and two in the upper floor for sleeping rooms, measuring each $38+28 \mathrm{ft}$. and about eleven in height. In this building all the children reside, with the exception of infants, and those so young as to require innmediate attention. The sleeping rooins are well ventilated. There is no work allowed to be performed in this building that can render the air impure, or incomınode the children. None but children and two female teachers reside in the building. There are play-grounds in the rear of the building, where the boys are allowed exercise in summer. The food for the children is cooked at the main building. The eatinghall for the children is in a small building between the asylum and the main building. It may with safety be said that there is not a better building, for the purposes to which it is appropriated, than this asylum, in the country. For it we are indebted to the exertions of A. Simonds, Esq. present Superintenderit, and some of the present Directors.

The diet of the children is as follows :-Breakfasts every day-milk thickened with wheat flour-bread, 2-3 wheat and 1-3 corn meal. This porridge is about 1-3 milk, 2-3 water. Suppers every day-milk and water boiled; about 1-2 milk, 1-2 water-bread cut fine and put in as they wish it. Dinners-Sunday, baked beef, mashed potatoes and bread. Monday, stewed beans and bread. Tuesday, beef soup, mashed potatoes and bread. Wednesday, boiled rice; or minced meat and bread; or mush and molasses. Thursday, saine as on Tuesday. Friday, minced fish and potatoes and bread. Saturday, same as on Tuesday.

The children are clad in summer in blue and white calico dresses; and in winter in flannel dresses with sufficient under clothes. 'They have woollen socks and shoes in winter, and go barefoot in summer. They are washed, in winter, every Saturday evening, over the whole body, and in summer oftener. The boys, during warm weather, in addition to this, are allowed to bathe in the open sea once or twice a week, according to the weather. Their hands and faces are washed certainly once a day, and very fiequently much oftener. Their heads, especially those of the smaller children, are conbed several times a week, sometimes daily. Their garments are changed every week as a rule; but those of the smaller children once, and perhaps twice a day, according to circumstances. Every child, when it enters the House, is immediately examined, and if any appearances are found of any contagious disease, it is not allowed to join the children at the asylum, till such disease is cured; if not, after being well cleansed, it is permitted to enter the asylum. Such are some of the main facts with reference to the place of residence and cleanliness of the children who are residents at the asylum.

More than two-thirds of these children are the offspring of debauched, or drunken, or half idiotic parents. Of those who died of measles, sequelæ, or of some disease complicated with measles, the most of them had parents of this character, as will be seen under the proper head. The usual number of children residing at the asylum is from 100 to 120 . One case, No. 43, Joses Solo, was in the Men's Colored House, so called, and was the only one among the inmates, properly so called, who 
had measles. So far as could be ascertained, he had had no communieation with the children, had not been at the asylum; nor had any of the children been near the building where he resided. From Men's Colored House to asylum is about 270 fcet.

February, 1836.

\section{ON TUE USE OF A VEgetable DIET.}

\section{To the Editor of the Boslon Medical and Surgical Journal.}

Sir,-l sometimes take notes, and make remarks in my note-bonk, respecting what I find upon the pages of your Journal. The note made after reading Mr. S. Graham's answer to Dr. Bell's Prize Essay, is from Dr. Jolunson-viz. Bolder words and more timorous meaning I never saw. Archimedes said that he could move this world if he only had another world to stand on. But to attempt to move the world, or its well-grounded custom of using animal food as a part of diet, so long and so well established, both by nature and by the Bible, and that with nothing to stand upon, is peculiarly Utopian. There is nothing in Mr. Graham's answer to the Prize Essay, worth notice, except that he makes Dr. Bell give up the argument derived from comparative anatomy, of man being a carnivorous animal. Whether Dr. Bell meant to be so understood, he can best decide himself. But upon this point, we would observe, that we should make man the standard, and as the organs of other animals approximate his, we should decide upon their carnivorous propensities. For, from his very earliest history, in the first chapter of that book - the oldest book in the known world - which gives an account of his creation, and that of the globe, we find that he had dominion given him over the fish of the sea, the first of all things whatever. Now why should fish have been made at all, and this dominion over them given, unless they were designed for the food of man? We find the dorninion of man extended, it is true, inmediately afterwards, over the fowl of the air, and over the cattle, and over all the earth; but fish preceded the whole. The fowl might bave been, and is, useful for its feathers, and beasts for their tallow and skins; but not so of edible fish. These have neither feathers nor fat.

But that the first man made an early use of other animal food than fish, is not lacking of that evidence which should be paramount. For in the same year in which he was created, we read of Adam and his wife being clothed in coats of skins. And it does not appear that these skins were taken off for the purpose of clothing, but that animals had been previously skinned for some other purpose. That this purpose was that their flesh might be used for food, is the only one that seems probable. We know that some commentators bere talk of sacrifices; but no institution of this kind had at that time been given, nor could sacrifices have preceded sin. And when sacrifices were afterwards established, the sacrificed animals were used as food by the priests and their families, thus sanctifying the use of animal food; and this use of animals; was also sanctioned by that law, which drew the line between beasts clean and 